\title{
Management of Risk in Microbusiness
}

\author{
Arjola Kaza \\ European University of Tirana
}

\section{Doi:10.5901/ajis.2016.v5n3s1p185}

\begin{abstract}
Good risk management is all about making the right decisions on how much risk should be taken, and how to handle the remaining risk. Done right, risk linked to given services is limited. It can be assessed using quantitative methods in order to identify the factors that influence it. Risk management is important in creating new growth opportunities and alleviating of poverty by way of job creation. Microfinance is even more important in this regard as it usually serves segments of population that are otherwise excluded from these services. It is a hard line to toe as serving a public interest role generally runs counter to the point of a business, namely generating profits. Every business has to at least be able to generate enough income to remain viable. In the microfinance world, that means that attention to detail has to be even more focused. Natural disasters or armed conflicts can't always be foreseen, however preparations on handling the outcomes of these events can be made well in advance. Careful and repeated screening and monitoring is needed to provide successful operations. Good risk calculation is based on solid information on new market opportunities as well as existing operations. Periodic evaluations and improvements can ensure a healthy financial situation and solid growth. Promoting a culture that encourages good risk management is proving to be quite a challenge.
\end{abstract}

Keywords: risk, financial situation, management, microbusiness

\section{Introduction}

Managers of businesses of all sizes face risk every day. Risk can come in many forms, some forms of it can be reduced or even eliminated by taking the proper precautions. Others are much more complex and therefore difficult to predict, hence a lot more effort should be dedicated to at least reduce them as much as feasible METE (2007). Operational risk is the risk a business takes to carry out the operation itself. If there no demand for the product or service the company thinks to provide, the business will fail. That is not enough however. Other very important considerations are whether said company is able to produce it, and at market price or cheaper than its competitors. Distribution, advertising and sales are all important components that carry risks. If advertising is not properly done, or the budget for it is over or under what it should be, profit will suffer. If distribution doesn't work correctly, despite having a ready market and demand for the product, it will still fail (Duffin 2009). This paper aims to provide a detailed overview of all the possible risks in SME-s and most importantly what can be done to manage them.

When a company grows, new risks arise (Ammann 2001). Is there going to be a market to absorb the additional output? Is the company going to be able to hire enough additional staff with the right set of skills to take the company to the next level? Is the production capability of the company high enough to accommodate the growth?

These are all risks that a business manager can anticipate, and be prepared for by hiring the right people for the job and by encouraging the right company culture. These are the basic risks a manager will face, that can only be reduced, not entirely eliminated. Other kinds of risks are totally out of the control of the decision makers, however, with the right tools and the right strategies can be totally planned for. In this category are included natural disasters like: earthquakes, flooding, fire etc. The strategy for hedging against natural disasters is usually insurance policies. They increase the overhead but seriously decrease uncertainty (Siddiqi 2005).

There are other risks as well, that cannot be predicted or totally prepared for such as: war, world economic crisis, emergence of new technologies that turn the business obsolete. These kinds of risks are harder to hedge for smaller businesses and much easier for bigger ones. That's because bigger businesses are usually global in today's world. They can diversify, both in their products and their business location. Microbusinesses on the other hand have a much harder time to cope with these kinds of risks because they are constrained to their local economy and location.

The ability of the management of Small and Medium Scale Enterprises (SMEs) to identify the risks that the companies face, and their ability to take the proper measures could mean success or failure (COM 2016). As such it is very important for every business organization regardless of size to take its risk management seriously. Businesses that 
fail to face problems in performance, and take no action to reduce or eliminate their exposure to risk, will likely fail at some point. The practice of risk management includes various tools such as proper book-keeping, insurance coverage against loss from natural disasters or malicious intents, and attention to both the world market and the local one. Predictable risk should be taken care of by proper management. Unpredictable ones can be taken care of by insurance coverage. Although the burden of insurance premiums would seem to be difficult for micro-businesses, it is actually worth the effort. This is because a natural disaster could easily wipe out entirely a micro-business, while it would only be an inconvenience to a bigger one.

Risk is a combination of the probability that some (dangerous) event will occur, and the consequences of it, if it actually occurs (Labodova, 2004). Two variables are identified: the probability of the risk event, and the magnitude of the event (meaning the outcome for the business if said event actually took place). So in essence, risk is the chance of an event happening that will have negative impact on the set goals.

On a broad perspective, a company faces two kinds of risks: systematic (undiversifiable risk), and unsystematic (or diversifiable risk). Systematic risks are the ones that every company in any industry or economy faces. A good example would be global economic condition, global inflation, recession, declining GDP and deteriorating of foreign reserves levels. These kinds of risks (also called pure risks), can't be handled by the right decisions of the management of a business. Unsystematic risks on the other hand, are unique to each company. They depend on the products or services provided, the industry in which said company operates, and are highly susceptible to the managerial decisions made. The latter decisions are usually taken care of by diversification whereas systematic risks are largely uncontrollable. A business will face risk at all stages of progress, start-up growth and exit. Starting a business is in itself a huge bet, and according to data, this is the stage that most businesses fail at. Requirements for micro-loans in microbusiness sector are high and they are undergoing a further rising due to the orientation of policies to a developed and competitive agriculture, facts these that have led to the increase of the production, to the orientation of farms towards commerciality, to the increase of exports, the increase of quantity and of the variety of processing of agricultural-livestock products during the recent years (IMF 2016). Despite the positive developments the banking system in Albania after 20 years now, lacks the financial courage and interest to increase lending in agriculture. Microfinance, with its institutions, as part of the system is the best, the fastest and the longest term choice for the agribusiness in Albania. Microfinance has the opportunity to identify areas in which there are insufficient services or financial products for this category of customers, it can identify potential of institutional partnership, aiming the decline of the cost of services or finding more efficient ways of providing them. The increase of lending capacity, the diversity of financial products and services, information and aggressive promotion of microfinance institutions, must definitely precede the development of agriculture, the expansion and growth of agribusinesses. Microfinance institutions should be consistent, reliable and supportive or at least they must have a clear perspective and future legal status. Diversifying the portfolio of services and cooperation with banking institutions helps the microfinance institutions to take advantage of banking technology and bank each product in terms of services (Bank of Albania 2016). Microfinance institutions should require their future in the responsible microfinance, in the minimization of risk, the advantages of products, diversification of loan products, transparency in providing product, promotion of small SME loans, etc. The government may be involved in microfinance by building a regulatory framework for supervision and the legal regulation of these institutions. Special laws are also needed when they mobilize deposits by the public. Central Bank can support microfinance with promotional activities as pilot projects, researches, publication and collection of data, qualifications, etc. It is already a requirement of time and a great challenge also for rural areas to create the Rural Bank, a bank, that will be subject of all the laws of banking system. This bank will fill that institutional and lending gap in the rural sector, by giving a boost not only to the objective of alleviating poverty, but even to the social and economic development of this sector (INSTAT 216)

Growth is also tricky. Even though it seems like it shouldn't be, sometimes moving to a higher level brings a much higher risk factor. This is because businesses seldom know how to deal with the new reality and take measures to improve their inefficiencies either too late or not at all. The exit strategy is also important. Getting out while on top is a well-known and seldom used practice.

Risk is unavoidable for any entrepreneur, therefore necessary for starting a business and growing. What is also necessary is a thorough and periodical performance examination. Thinking for too long may hamper the ability of a business to change, improve and progress, but not thinking in-depth about the next steps could have severe consequences. Therefore a delicate balance must be kept. Entrepreneurs by their very nature are less risk averse than other people. Successful ones are cherished and encouraged, because, in addition to being bold, they are individuals that think ahead as well, and quickly, or they wouldn't be successful (World Bank 2016).

Risk Management is a term usually linked to major corporations, but it would help Medium and Small businesses 
just as much or more. Being that small businesses are historically the biggest employers in economies, both Western developed economies and less developed ones - how small business do is generally how an economy does. We have seen politicians from all sides of the political discussion talk about the importance small businesses have on the Albanian economy and how important it is to support them, but very little has been done to-date (AEDA 2016). With the Justice Reform entrepreneurs and businesses across the country would feel much more encouraged to try and compete for a bigger piece of the pie as less corruption would mean an even plain field for the best managed companies to succeed.

\section{Conclusion}

In conclusion SME-s can flourish by using proper managerial tools both in decision-making and in risk-reducing measures (such as insurance policies), and if the New Justice Reform would actually be implemented, it would allow the best companies to rise to the top and become slowly global players just like other businesses from countries all over the world).

The importance of risk management can hardly be overemphasized. SME-s are becoming more and more aware of the importance of risk management. This is because we are living in a less stable economic and political environment.

A strong risk management has always been a challenge for many SME-s. They all share the same doubt: "How much should be spent to prevent a disaster that might never happen? SME-s are often afraid of taking on debt, meaning investing in strategies that can prevent risk. Nevertheless an investment in risk management is crucial. It is vitally important for each small and medium enterprise to develop a strong and solid risk management programme.

In achieving this, companies should start by pointing out their most serious threats to their revenues and profits, and making a clear distinction between those that are mainly downside risks and those that are mainly variable risks. SME-s should try to maintain proper accounting, in order to handle the risk effectively. Having a safe risk management strategy goes a long way toward the success of an enterprise. On the other hand insurance companies should make SME-s aware of the importance of insurance policy in order to manage risk.

One cannot be innovative without taking risk. New business owners enter the market with new and innovative ideas or products which aim at making something better or making something new. But the smaller the business, the more likely it is that its survival will largely depend on effective risk management.

\section{References}

The strategy of business development and investments (2007-2013) (2007), METE June

Duffin (2009). Credit Risk: Pricing, Measurement, and Management.

Ammann (2001). Credit Risk Valuation: Methods, and Models Applications. Churchill, C. Microfinance Handbook Manangement Risk.

Siddiqi (2005). Credit Risk Scorecards: Developing Intelligent Implementing and Credit Scoring.

Albania Progress Report, COM 2016, Brussels

Labodova, A. (2004). Implementing integrated management systems using a risk analysis based approach. Journal of Cleaner Production, 12(06), 571-580.

International Monetary Fund: http://www.imf.org

Bank of Albania: http://www.bankofalbania.org

Institute of Statistics INSTAT http://www.instat.co.al

World Bank: http://www.worldbank.org

Albanian Economic Development Agency AEDA: http://aeda.gov.al 